\title{
AERIAL PHOTOGRAPHS: A TOOL FOR COASTAL ENGINEERING STUDENTS
}

\author{
Pablo Cabrera ${ }^{1}$, Gabriel Chamorro², Bismarck Jigena ${ }^{1}$, Luis Moreno ${ }^{3}$, Juan J. \\ Muñoz-Perez ${ }^{1}$ \\ ${ }^{1}$ University of Cadiz (SPAIN) \\ ${ }^{2}$ University of Seville (SPAIN) \\ ${ }^{3}$ Politechnic University of Madrid (SPAIN)
}

\begin{abstract}
Different methodologies have already been applied in different countries to teach Coastal Engineering (CE) trying to improve the learning process due to their inherent difficulty [1]. The large number of academic failures has been reduced [2] by the use of new and old technologies like audio/visual resources [3] or "rules of thumb" [4] respectively.
\end{abstract}

CE has experienced a rapid growth in the last fifty years. And though it has a high mathematical and physical load, understanding the coastal processes through empirical observation is of great help for learning. The new Information Technology (IT) tools have allowed advancing both in the field of theoretical investigation as in the practical application of easily observable phenomena. Especially important is the possibility of using visors of aerial photographs, which allow not only to study a specific situation at a given date, but also the time evolution over the years. The use of Internet applications such as Google Earth opens up many possibilities of study in a very simple way [5]. Therefore, with a basic knowledge on maritime works, it is possible to obtain expressions or mathematical models through free available information, which serve to realize pre-designs of possible solutions or to analyze the certainty of a final solution. These easy-to-apply methodologies let also to evaluate the success or failure of maritime works already executed, and is useful in cases of inability to conduct complete studies of coastal dynamics.

Application of these free tools is fundamental to carry out the monitoring of already built maritime works. A suitable treatment of this information allows the realization of new designs in an easier and intuitive way. Moreover, it facilitates the interpretation of coastal processes by engineering students who come for the first time to this topic. Prof. Iribarren, one of the foremost exponents of CE in Spain, based much of his findings on the observation of the sea with a high degree of intuition. For those who do not have that ability to intuit, the tools described previously may be a way to achieve an easier and better understanding of the Coastal Engineering subject.

Keywords: innovation, IT, Google Earth, e-learning.

\section{INTRODUCTION}

The civil engineering studies are mainly practice, with a big academic load in mathematics and physics. The use of new technologies has experienced a great advance thanks above all to the emergence of computers, that allow very complex mathematical methods. That is the reason why learning the ability of using specialized computer software has become so important. This software can represent any situation of calculation and design of structures, roads, and any other type of civil work in general.

Nevertheless, knowledge of the phenomenon to be characterized is essential for the application of these new techniques and methodologies. Most of specialized civil engineering software is too friendly turning this fact into a problem as there can be uncertainty in results due to the assumptions and adjustments of the input parameters [6]. Therefore, it is very important that the engineer dominate not only the software, but also the nature of phenomenon which is studying in order to be able to perform a correct interpretation of the retrieved results and avoid important errors.

There are some classical and popular fields of study in civil engineering where students intuitively have a prior knowledge that allows them to learn more easily the models and theories used. For instance, a crack in a structure or on a road, or a failure in the foundations of a building, are cases to easy understand by the students, for two fundamental reasons: First of all, they are easy to see in their daily lives, and secondly most of the academic training is intended to study those cases. 
However, there are other areas of engineering whose nature and processes are more difficult to assimilate due to temporal and spatial scale problems. It's easy to find a crack in a beam that is poorly designed, and start a monitoring of the progress of the break every day. But it's very complicated to study if a beach gains or loses sand from one day to the next, to find out if it is a definitive or temporary trend, if it is a problem or not...or just if this is the way a beach works, its natural behavior before the natural processes.

Coastal engineering needs an initial learning of the student of civil engineering to understand perfectly not only why a beach changes due to natural processes (waves, wind, etc.), but also before possible actions of the man (maritime works, ports, beach nourishments, etc.). Moreover, the student must afford the coastal forms that are generated because all these interactions.

Internet offers the possibility of acceding to a great collection of aerial photographies, and the creation of platforms or tools that allow arranging all this information in the space and in the time. This way, concepts that can be abstract for a student at first, turn in intuitive and easy to identify at the end of a learning session based on air images. It is possible that the use of these tools helps meet with certain requirements in the design of the projects of construction.

\section{EXAMPLE OF A METHODOLOGY FOR THE EXPLANATION OF CONCEPTS OF COASTAL ENGINEERING WITH AERIAL PHOTOGRAPHS}

\subsection{Need to establish a methodology. Advantages}

There exist concepts in engineering that are represented by means of more or less complicated mathematical expressions, but that are easily identifiable by means of the direct observation. For example, the mathematical expression that represents the deformed shape of a beam due to a load.

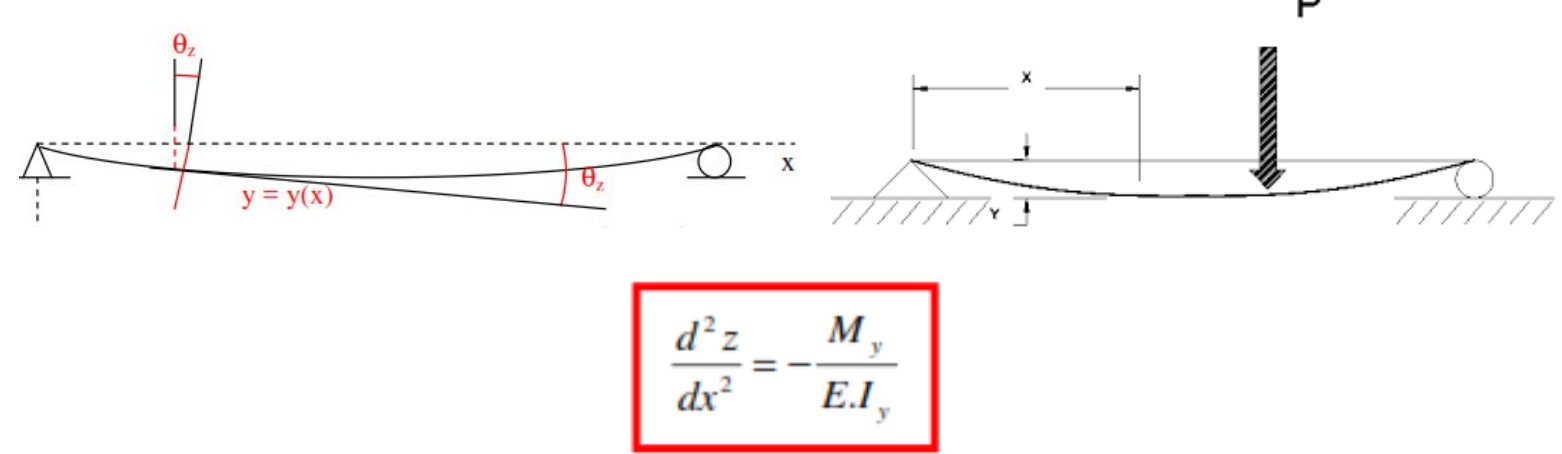

Fig. 1 Graphical representation and mathematical expression of the deformed shape of a beam.

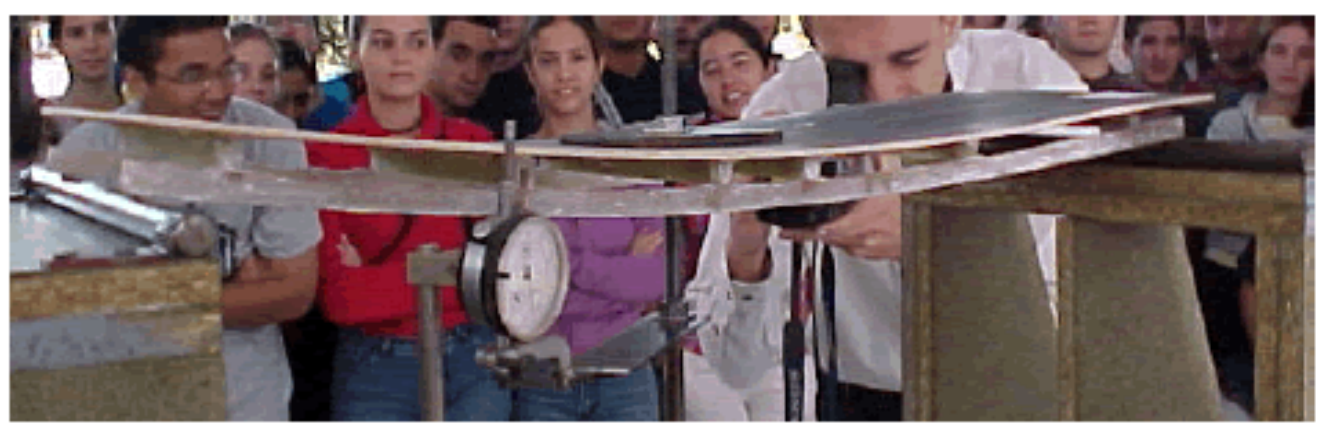

Fig. 2. Example of practical representation of the deformed shape of a beam due to a load

It is a not very complicated expression, with a simple and easily recognizable representation in the reality that can be represented by means of a practical easy exercise. In addition, civil engineering students use similar concepts that define the above mentioned mathematical expressions from the first course of the career: moment of inertia, bending moment, module of elasticity, etc

But, what does happen when a teacher begins to teach a subject with totally new concepts and with new mathematical expressions not studied before? It is necessary to acquaint the student with these 
new concepts. Otherwise, two very habitual problems can be provoked. First, that the student learns everything by heart, but without understanding what he studies. Secondly that the student is not attracted by the subject because he does not understand the relationship between the theory he studies and reality.

Coastal engineering is a good example of this problem. It is a part of the engineering that has developed enormously in the last years, but it is based on concepts of coastal processes which are relatively simple, but sometimes complicated to explain by means of just mathematical expressions. That is the reason why the use of aerial photographs facilitates enormously learning of strange new concepts in a rapid and adapted way.

This methodology can be divided into three points:

1 Choice of the concepts adapted for the explanation by means of aerial photographs.

2 Search of the aerial photographs in base of existing information, with two possibilities of work:

a) Database and files of Administrations or consultation of projects or studies already realized that contain this information.

b) The use of tools and Internet platforms that contain already processed aerial photographs

3 Preparation of the session of the class with the whole documentation, including in addition practical examples to solve in the same class to assure the understanding of the showed concepts by the student. It is necessary to arrange the minimal necessary equipment: a computer, projection screen and internet access, no forgetting the useful traditional blackboard.

It is advisable the use of software or Internet applications that could facilitate all this process. Many of the processes and concepts of coastal engineering are affected by the scale of the space and of the time, and it is necessary to be able to represent space and time in the selection of aerial photographies that are used. The new Information Technology (IT) tools have allowed the use of visors of aerial photographs which allow check time evolution in any site of the littoral with different scales. In addition, these visors allow performing several steps of mentioned previously in an easy and rapid way.

The most widespread visor, besides being the most easily completed with exterior information files, is the Google Earth application. Other two advantages are:

1 Possibility of consulting and using google earth in a computer, in a mobile, or in a tablet. Every student can have his own visor in class and can practice with it. Pace learning becomes much more agile and being able to establish a high level of participation.

2 There exists a professional version of free access, google earth pro, which allows many more options of work.

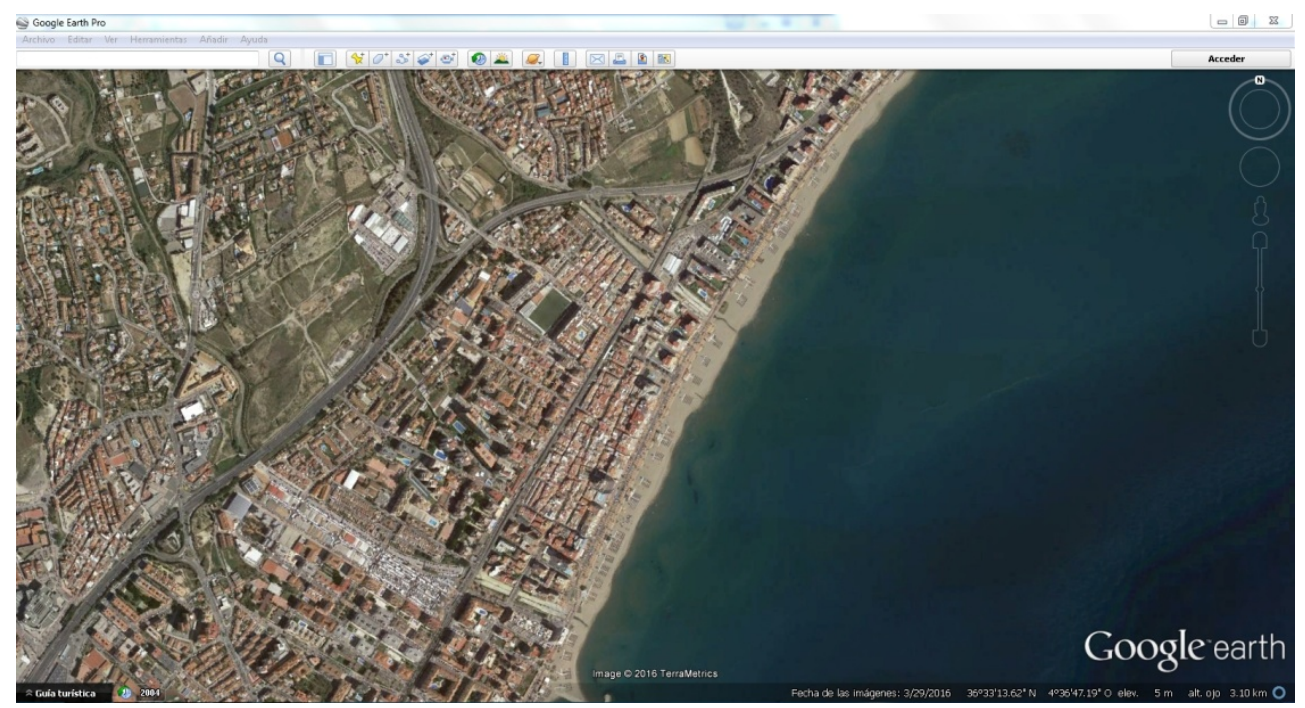

Fig. 3 Example of an aerial screenshot of Fuengirola Beach (Malaga, Spain) by means of Google earth pro. 
There exist some other different visors like bing maps, or web with visors which show images of other data source, e.g. mapadebolsillo.com or iberpix in Spain or for example:

- https://www.ign.es/ign/layout/faimsatinicio.do, belonging to Geographical national institute of España.

- http://sig.magrama.es/dpmt/, belonging to Headquarter of Sustainability of the Coast and the sea, Spain. (fig 4.a)

- http://eros.usgs.gov/aerial-photography, belonging to EROS Center, USA. (fig 4.b)

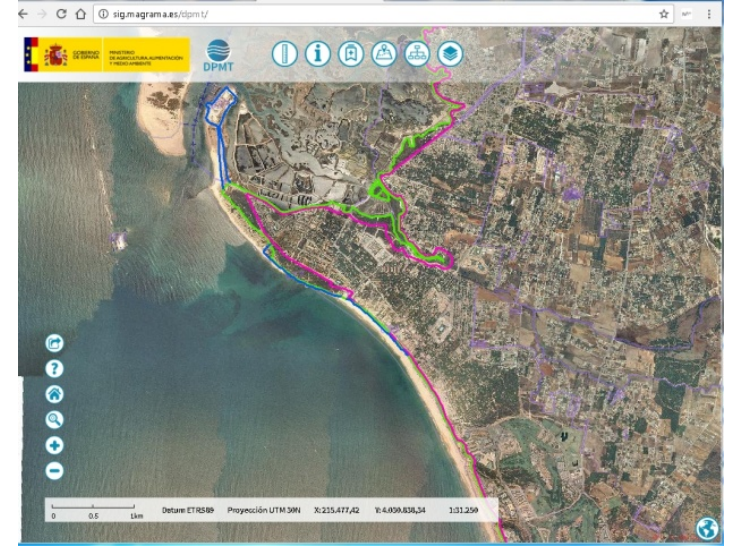

(a)

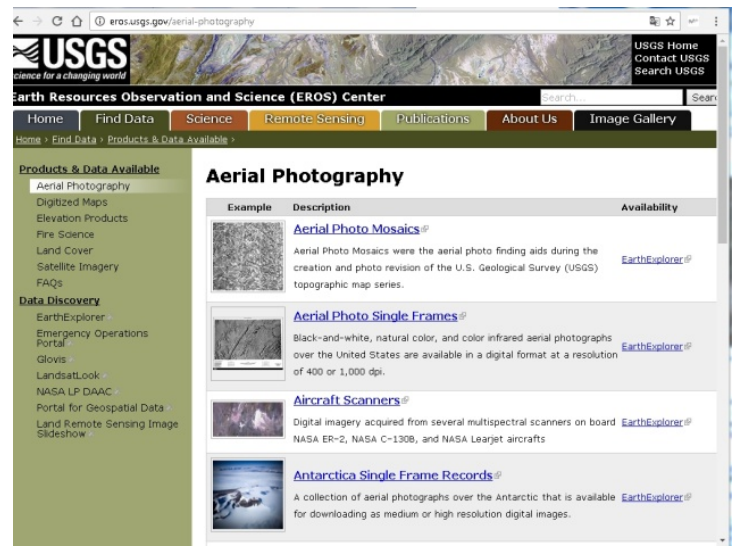

(b)

Fig 4.

\subsection{Information and possibilities offered by a visor. Example with google earth}

Information and possibilities offered by a visor, as you can see in the example of google earth (Fig. 59 ), are great and very interesting. Those possibilities that are considered more interesting for the proposed aims are commented below:

1 Possibility of choosing different scales of observation.
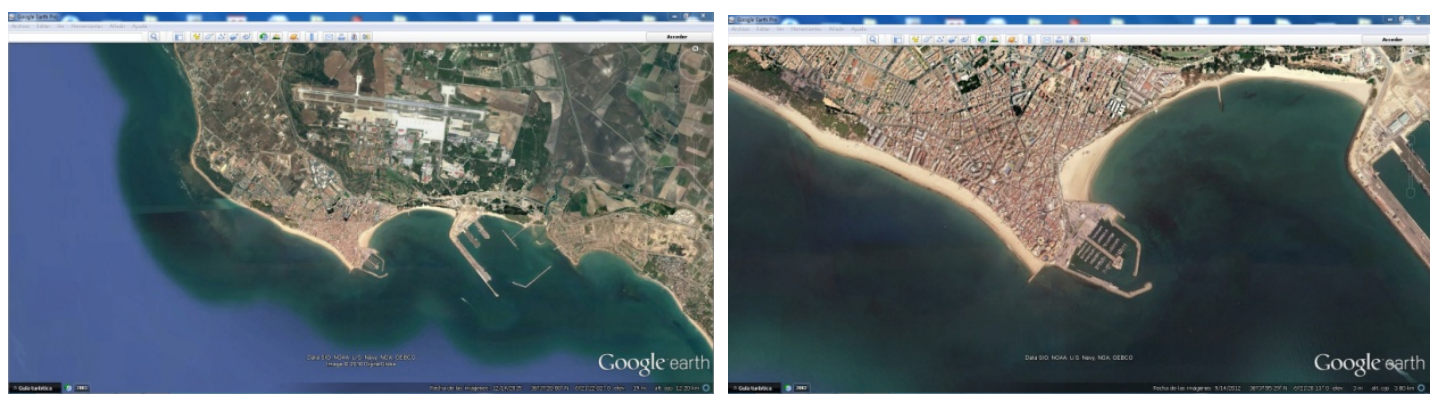

Fig 5 Aerial views of Rota Harbor (Cadiz, Spain) at different elevations and, consequently, different point scales.

2 Possibility of checking the same emplacement of the coast in several different dates. 

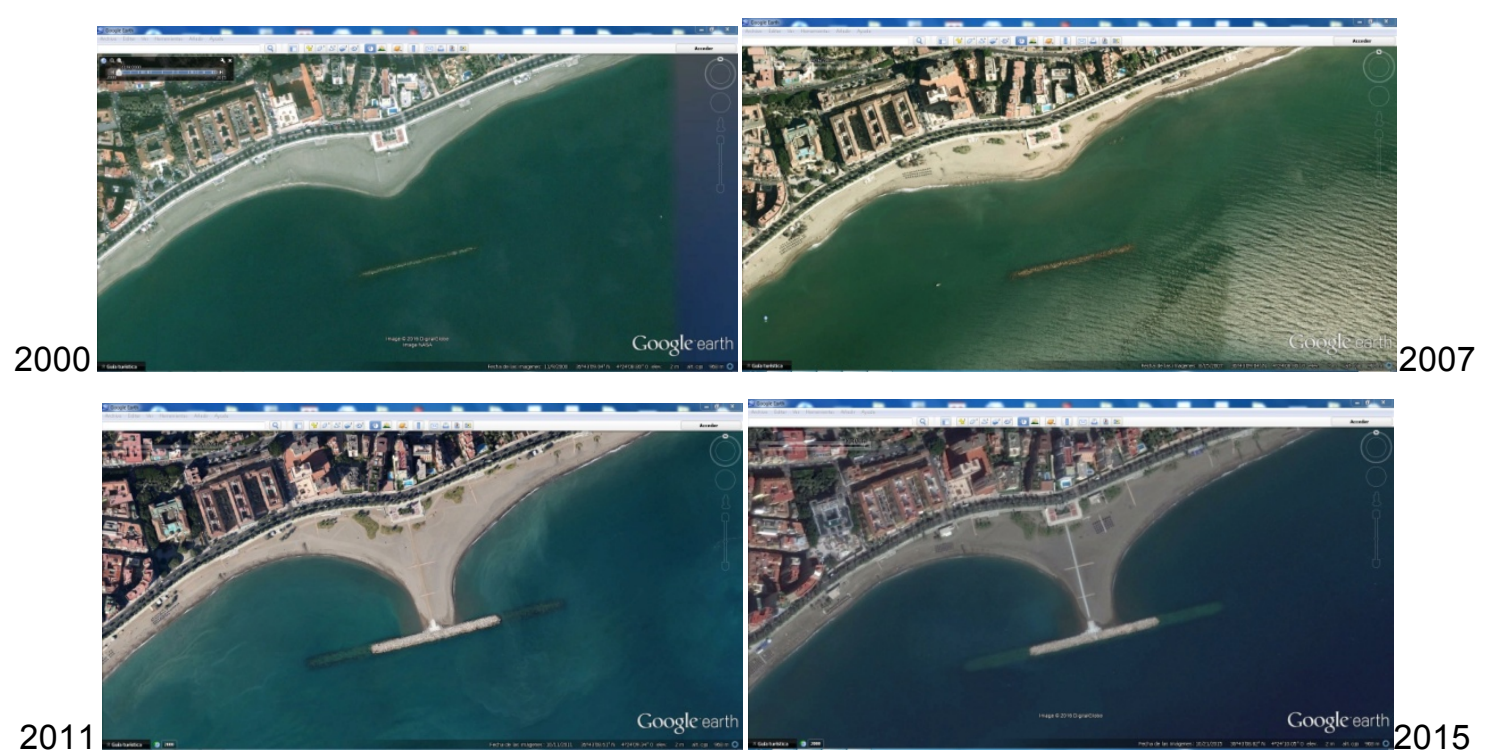

Fig. 6. Example of Breakwater in Malagueta Beach (Málaga, Spain).

3 Possibility of including additional information of other databases:

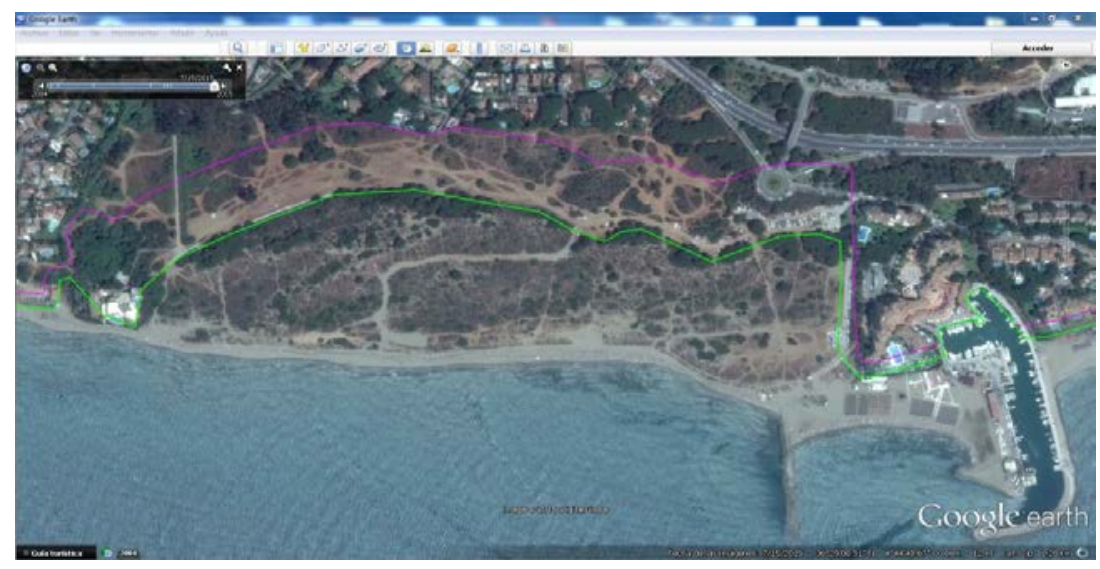

Fig 7 Artola Beach \& dunes (Marbella, Spain). The green line defines the public domain. The purple line defines the limit of possibility of house construction. Line obtained by file type $\mathrm{kmz}$ from Coastal Department of Mediterranean Andalusia (Spain).

4 Possibility of visualizing photographs of exterior databases with:

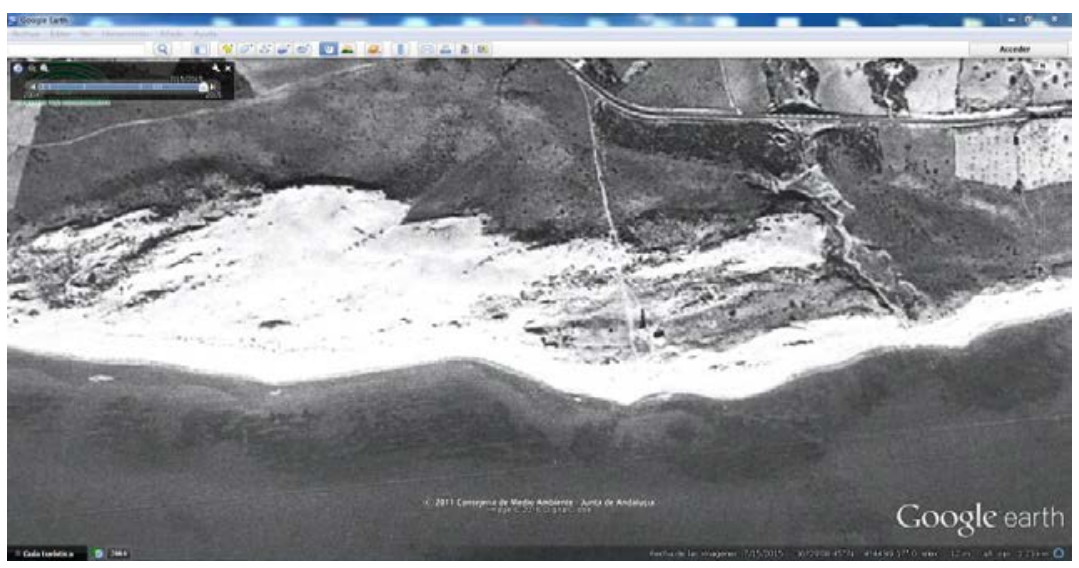

Fig 8 Artola Beach \& dunes (Marbella, Spain) in 1956, "the american flight", obtained from Junta de Andalucia. 
5 Possibility to mix and to exchange all the information before commented

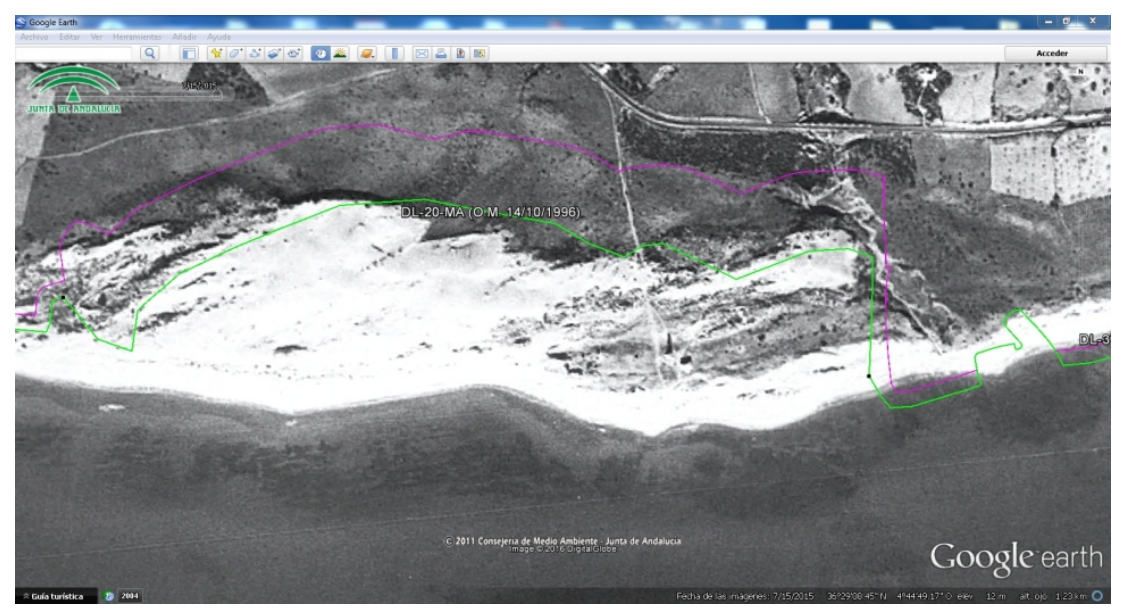

Fig 9 Artola Beach \& dunes (Marbella, Spain)The green line defines the public maritime terrestrial domain on the aerial photograph of 1956.

\subsection{Example of coastal engineering concepts explained by means of air photographs}

\subsubsection{The geometry according to equations of coastal shape curves}

Practical application of explanation by means of curves of logarithmic spirals can be represented in aerial views of shores supported on ports and other maritime works
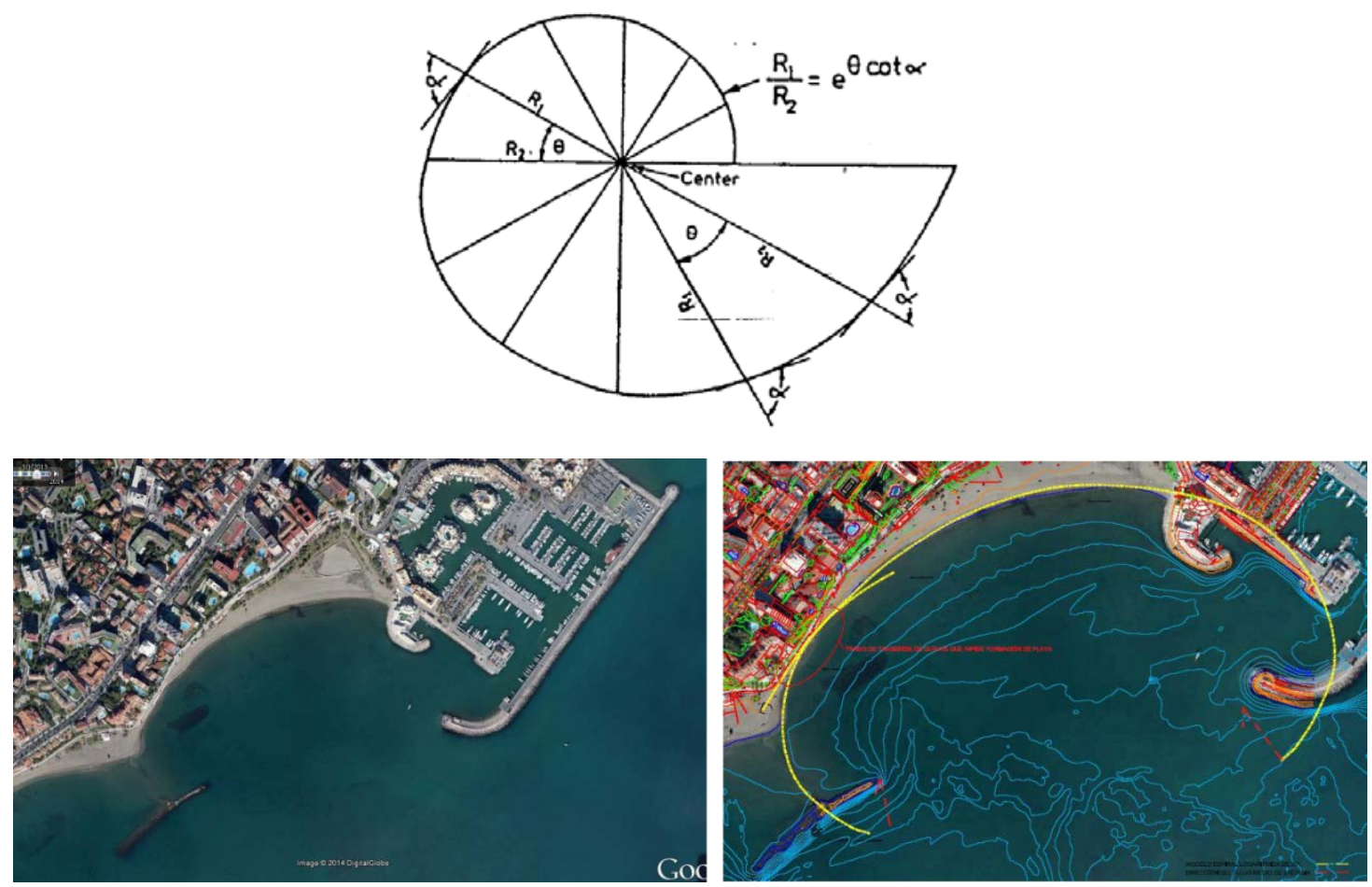

Fig.10. Malapesquera Beach (Benalmádena, Spain).

Application of logarithmic spiral function to the plan shape.

\subsubsection{Estimation of the direction of Littoral Sediment Transport.}

Observation of the direction of the littoral sediment transport (ST) parallel to the coast, and how it can change the alignment of the shore into a beach, according to the direction of the above mentioned ST 


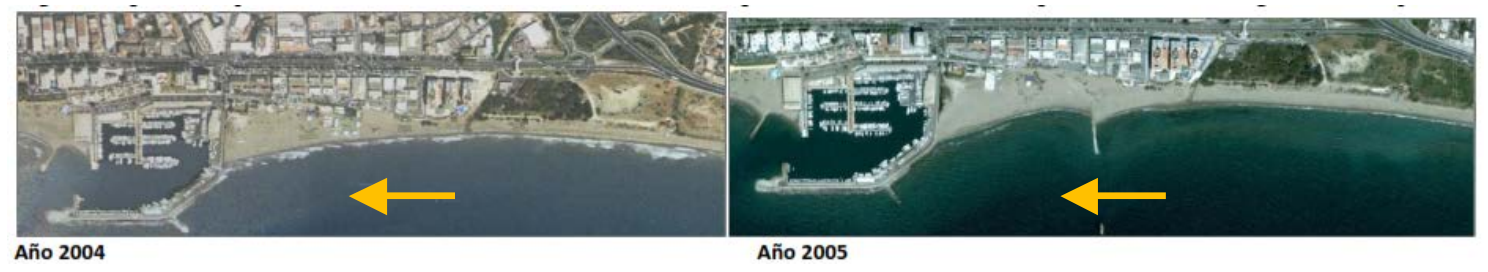

Fig. 11 El Cable Beach (Marbella, Spain). Direction of the clear ST, and variation of the shore alignment due to changes or works that concern the ST.

\subsubsection{Design of planes of evolution of lines of shores}

Design of plan representation with evolution of shorelines by means of the observation of shores of different flights along different years. Therefore, the study of the general evolution of the coast is possible, taking into account erosion, accretion and the beach width evolution.

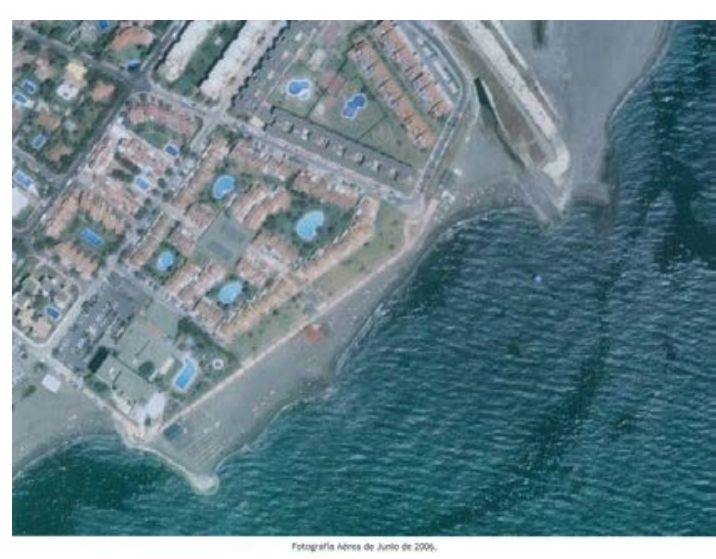

2000

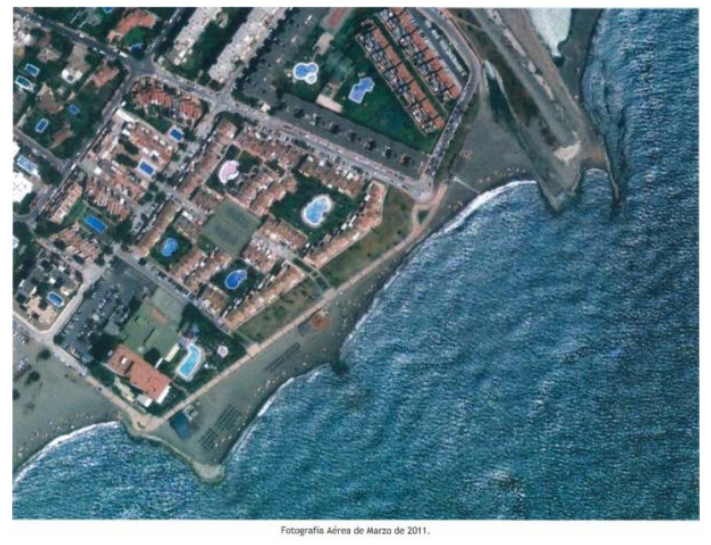

2011

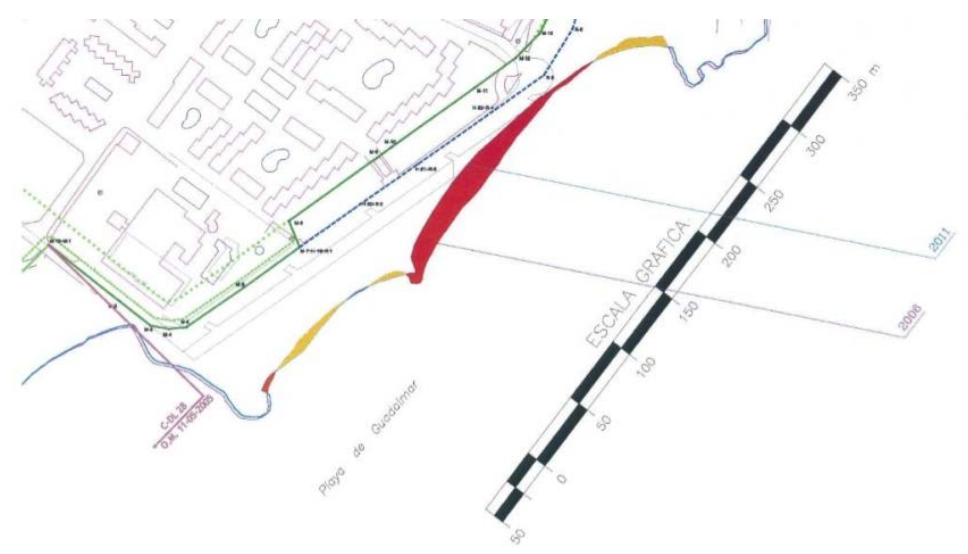

Evolución de las lineas de orillas desde 2006 a 2011.

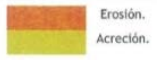

Fig. 12 Guadalmar Beach (Málaga, Spain). Example of how obtaining maps of shoreline evolution from aerial photographies.

\subsubsection{Example of obtaining shoreline evolution from aerial photographies.}

It is possible to explain easily the effects that construction or other anthropic actions have on the coast by means of sand nourishment or extraction, execution of seaside promenades or buildings in the dry beach, etc. 


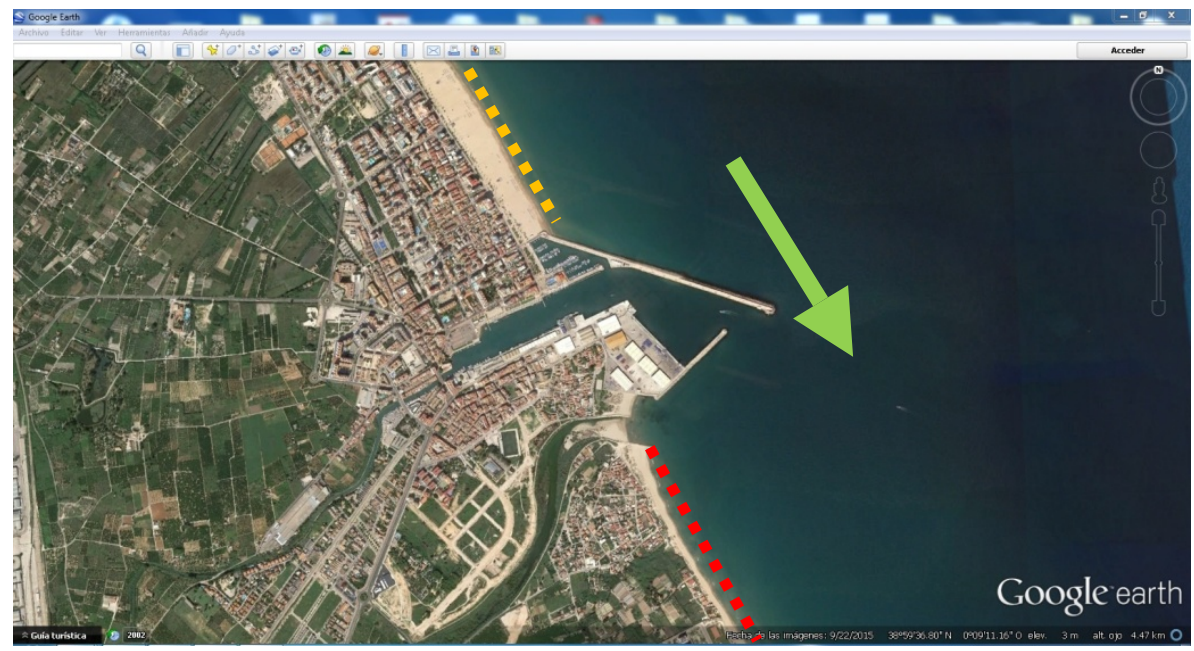

Fig. 13 Port of Gandía. Difference between accretion (yellow) and erosion (red) due to the construction of the port, associated with the direction of the ST (indicated with a green arrow).

\section{CHECKING OF THE EFFICIENCY OF THIS LEARNING METHODOLOGY}

This methodology has been one of the principal bases in the learning of coastal engineering course in Civil Engineering studies in the university of Seville (Spain). To verify its efficiency, during the first class, some of the previous concepts were explained by the use of aerial photographies and two practice exercises were proposed. The number of students attending the class was 35 . None of them had a previous contact with the subject, or studied concepts of coastal engineering.

The first exercise consisted of drawing the direction of the ST in different aerial photographies, according to the coastal forms that were observed:
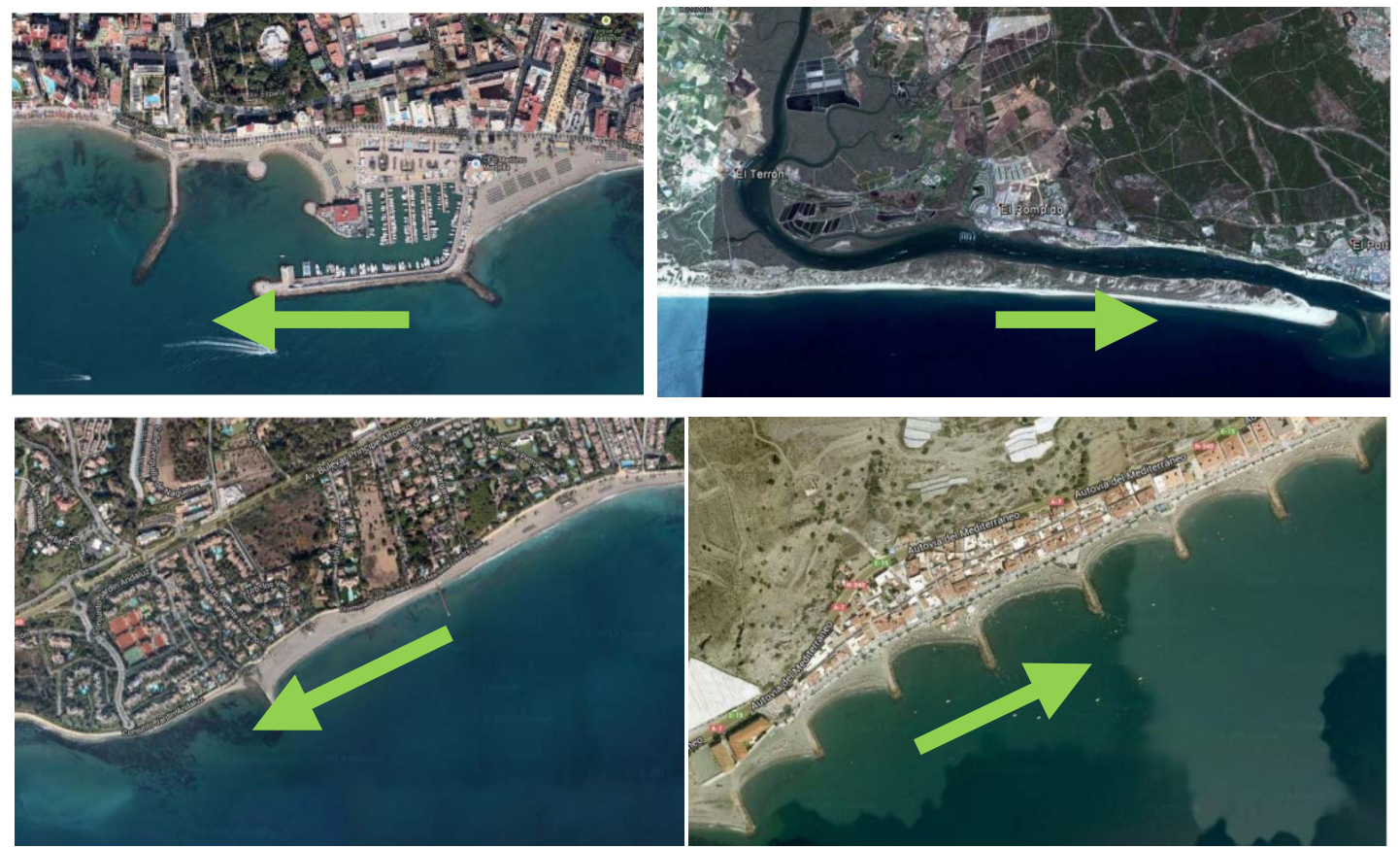

Fig. 14.

$100 \%$ of the students were capable of drawing the correct sense in the four presented cases.

The second exercise consisted on drawing the possible equilibrium plan shape of a beach according to the drawing of a series of maritime existing works, and considering null ST. 


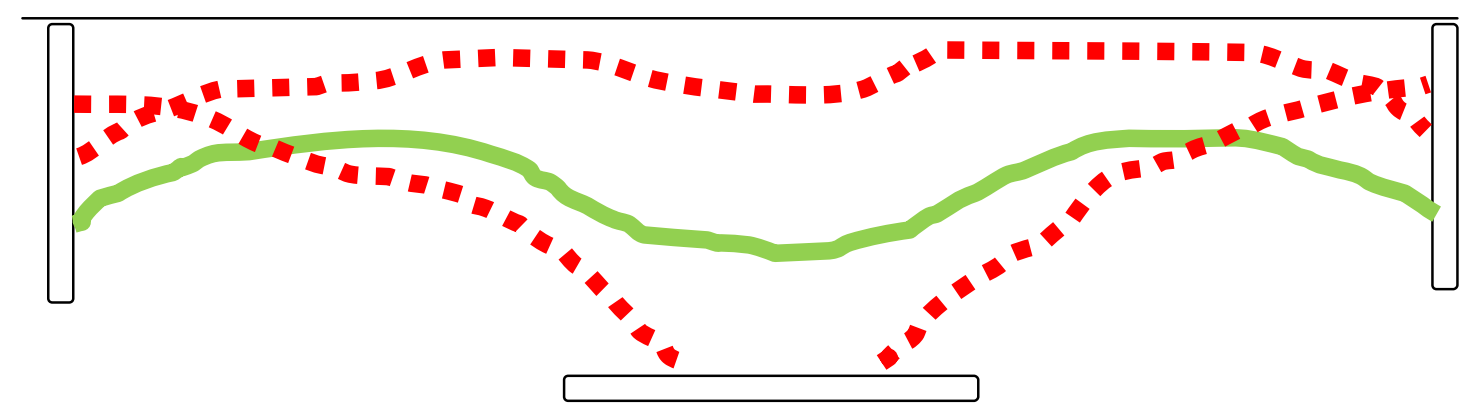

Fig. 15 Second exercise.

The green line is the most ideal solution, while red lines represent the envelope curve of all the solutions. Actually, all the solutions proposed by the students were following concepts showed in class. The aim was not to draw an ideal line of the shore, but sketching a shoreline that could adapted to the presented case, bearing in mind that no information about large scale not temporary changes was given. This fact demonstrated that the aim of the methodology applied to the learning of the coastal engineering allowed a rapid comprehension and assimilation of the concepts of the coastal processes. This allows a solid base to advance rapidly in other more complex concepts.

\section{CONCLUSIONS}

The tools and methodology proposed herein suppose observation of the natural phenomena of the sea from the same classroom. Observation is undoubtedly one of the best weapons to understand coastal processes. But processing of aerial photographies by using spatial and temporary scales is a tool which allows advantages over a direct in situ observation. In this case, the new technologies allow returning to the most ancient method to study the nature discovered by the man: the observation. Moreover, this aptitude is improved by disposing of complementary information both in time and in space. This proficiency enables the students to advance more rapid in the learning of the most complex methodologies as finite elements or the use of complex software, but from a consistent and deeply rooted basis: the assimilation of natural phenomena.

\section{REFERENCES}

[1] Neves M.G., Fontul S., Miguez M., Solari S., Muñoz J.J. (2015). Methodologies for teaching an engineering subject in different countries: comparison and results. INTED2015 Proc., pp. 13391346.

[2] Navarro-Pons M., Moreno L., Muñoz-Perez J.J., Anfuso G., Román-Sierra J. (2014). Success on increasing number of students that pass the coastal engineering subject. EDULEARN14 Proc., pp. 4443-4448.

[3] Lopez-García P., Navarro-Pons M., Muñoz-Perez J.J., Anfuso G. (2014). Audiovisual resources as a useful tool to improve the teaching of coastal engineering (Marine Science BSc degree). EDULEARN14 Proc., pp. 6117-6124.

[4] Chamorro G., Cabrera P., Muñoz-Perez J.J. (2016). A return to the "rules of thumb" in maritime engineering for digital native students. ICER'16, Seville (in press).

[5] Jigena B., de Gil A., Walliser J., Vidal J., Muñoz-Perez J.J. (2016). Improving the learning process in the subject of basic maritime training using GPS and Google Earth as useful tools. INTED2016 Proc., pp. 6161-6171.

[6] Muñoz-Pérez, J. J., Caballero, I., Tejedor, B., \& Gomez-Pina, G. (2010). Reversal in longshore sediment transport without variations in wave power direction. Journal of Coastal Research, 780-786. 